\title{
Design and properties of a novel radiopaque injectable apatitic calcium phosphate cement, suitable for image-guided implantation
}

\author{
Myriam Le Ferrec,' Charlotte Mellier, ' Florian Boukhechba, ${ }^{1}$ Thomas Le Corroller, ${ }^{2}$ \\ Daphne Guenoun, ${ }^{2}$ Franck Fayon, ${ }^{3}$ Valerie Montouillout, ${ }^{3}$ Christelle Despas, ${ }^{4}$ Alain Walcarius, ${ }^{4}$ \\ Dominique Massiot, ${ }^{3}$ Franc, ois-Xavier Lefèvre, ${ }^{5}$ Caroline Robic, ${ }^{6}$ Jean-Claude Scimeca, ${ }^{7}$ \\ Jean-Michel Bouler, ${ }^{5}$ Bruno Bujoli ${ }^{5}$ \\ ${ }^{1}$ Graftys SA, Eiffel Park, Bâtiment D, Pôle d'activites d'Aix en Provence, 13854 Aix en Provence CEDEX 3, France \\ ${ }^{2}$ Hôpitaux Sud - Hôpital Sainte-Marguerite, CHU APHM, 13274, Marseille Cedex 9, France \\ ${ }^{3}$ CNRS, UPR 3079, CEMHTI, 45071 Orleans Cedex 02, France \\ ${ }^{4}$ Universite de Lorraine, CNRS, UMR 7564, LCPME, 54600 Villers-lès-Nancy, France \\ ${ }^{5}$ Universite de Nantes, CNRS, UMR 6230, CEISAM, UFR Sciences et Techniques, BP 92208, 44322 NANTES Cedex 3, France \\ ${ }^{6}$ Guerbet, Bâtiment Rimbaud, 93420 Villepinte, France \\ ${ }^{7}$ Universite Côte d'Azur, CNRS, Inserm, iBV, UMR 7277, Tour Pasteur, UFR Medecine, 06107 Nice Cedex 02, France
}

Received 12 September 2017; revised 9 November 2017; accepted 18 November 2017

Published online 00 Month 2017 in Wiley Online Library (wileyonlinelibrary.com). DOI: 10.1002/jbm.b.34059

\begin{abstract}
An injectable purely apatitic calcium phosphate cement (CPC) was successfully combined to a water-soluble radiopaque agent (i.e., Xenetix ${ }^{\nabla}$ ), to result in an optimized composition that was found to be as satisfactory as poly(methyl methacrylate) (PMMA) formulations used for vertebroplasty, in terms of radiopacity, texture and injectability. For that purpose, the Xenetix dosage in the cement paste was optimized by injection of the radiopaque CPC in human cadaveric vertebrae under classical PMMA vertebroplasty conditions, performed by interventional radiologists familiar with this surgical procedure. When present in the cement paste up to $70 \mathrm{mg} \mathrm{I} \mathrm{mL}^{2}$, Xenetix did not influence he injectability, cohesion, and setting time of the resulting composite. After hardening of the material, the same observation
\end{abstract}

was made regarding the microstructure, mechanical strength and alpha-tricalcium phosphate to calcium deficient apatite transformation rate. Upon implantation in bone in a small animal model (rat), the biocompatibility of the Xenetix-containing CPC was evidenced. Moreover, an almost quantitative release of the contrast agent was found to occur rapidly, on the basis of in vitro static and dynamic quantitative studies simulating in vivo implantation. $\vee 2017$ Wiley Periodicals, Inc. J Biomed Mater Res Part B: Appl Biomater 00B: 000-000, 2017.

Key Words: calcium phosphate, radiopaque agent, injectable cement, image-guided implantation, bone reconstruction

How to cite this article: Le Ferrec M, Mellier C, Boukhechba F, Le Corroller T, Guenoun D, Fayon F, Montouillout V, Despas C, Walcarius A, Massiot D, Lefèvre F-X, Robic C, Scimeca J-C, Bouler J-M, Bujoli B. 2017. Design and properties of a novel radiopaque injectable apatitic calcium phosphate cement, suitable for image-guided implantation. J Biomed Mater Res Part B 2017:00B:000-000.

\section{INTRODUCTION}

Calcium phosphate cements $(\mathrm{CPCs})^{1-7}$ are now widely used for bone void filling and have obtained regulatory approval in many countries in Europe, America, and Asia. In particular, injectable CPCs give access to implantations under minimally invasive surgery conditions with high benefits (small incision, rapidity, and low complication rates), due to their injectable character, and act as a mechanically resistant sacrificial calcium phosphate source for bone reconstruction. For example, we have codeveloped two injectable formulations of these bioactive bone substitutes which are on the market since 2008. ${ }^{8}$ These CPCs benefit from $>8$ years of clinical experience and have proven efficiency in traumatology. ${ }^{9-11}$ Histological and radiographic data of clinical cases performed by clinicians have indeed shown bone reconstruction and quasitotal resorption of the CPCs within 1218 months, and analysis of the newly formed bone gave evidence of its excellent quality.

However, substantial improvements are still needed to extend their application in spine (e.g., filling of cages for intervertebral fusion, vertebral body augmentation), in particular the inclusion of an adapted contrast agent (i.e.,

Additional Supporting Information may be found in the online version of this article.

Correspondence to: B. Bujoli; e-mail: bruno.bujoli@univ-nantes.fr

Contract grant sponsor: OSEO; contract grant number: F1210010

Contract grant sponsor: Graftys Company

Contract grant sponsor: TGIR RMN THC FR3050 
TABLE I. Characteristic Parameters of CPC/Xenetix Combinations as a Function of the Contrast Agent Loading ( $\mathrm{mg} \mathrm{I} \mathrm{mL} 2^{1}$ of Cement Paste): Initial Setting Time Monitored at 378C Using Gillmore Needles, Compression Strength Measured after 72 h, Amount of $a$-TCP Transformed into CDA Versus Time Measured From ${ }^{31}$ P MAS NMR Spectra

\begin{tabular}{|c|c|c|c|c|c|c|}
\hline lodine concentration in the cement paste $(\mathrm{mg} \mathrm{l} / \mathrm{mL})$ & 0 & 36 & 46 & 56 & 70 & 80 \\
\hline $\begin{array}{l}\text { Percentage of Xenetix } 350 \text { introduced in the liquid phase } \\
\text { (\% by volume) }\end{array}$ & 0 & 36 & 46 & 56 & 70 & 80 \\
\hline$t_{\mathrm{i}}(\min )$ & 761 & 861 & 861 & 961 & 1161 & 1561 \\
\hline Compression strength (MPa) & 2262 & 1962 & 2061 & 2062 & 2062 & 1462 \\
\hline Amount of $a$-TCP transformed into CDA (\%) versus time & $\begin{array}{c}0(t 50) \\
21(6 \mathrm{~h}) \\
75(72 \mathrm{~h}) \\
87(2 \text { weeks })\end{array}$ & $\mathrm{nd}^{\mathrm{a}}$ & nd & $\begin{array}{c}0(t 50) \\
16(6 \mathrm{~h}) \\
71(72 \mathrm{~h}) \\
82(2 \text { weeks })\end{array}$ & nd & nd \\
\hline
\end{tabular}

\footnotetext{
a nd, not determined.
}

compatible with the bioresorption of the associated cement) to assist their implantation under image-guided procedures, since the opacity of CPCs is close to that of bone tissues. Filling this gap is highly strategic, since the fast improvement of imaging technologies should result in their increasing use in operating rooms. Indeed, interventional radiology has contributed to some of the most significant medical improvements in recent years, including overall survival,12 quality of life improvement for patients ${ }^{13}$ and reduced healthcare costs. The current state of the art in the field mainly concerns image-guided bone augmentation with injectable poly(methyl methacrylate) (PMMA) resins that are used for over two decades to treat fractures related to osteoporosis in different locations. In particular, a steady increase in the use of vertebroplasty is observed, consisting in the augmentation of vertebral compression fractures by image-guided intracorporeal injection of PMMA, in order to palliate pain after failure of noninvasive therapies. ${ }^{14,15}$ However these resins are not biodegradable and contain barium sulfate particles for their visualization under fluoroscopy. From the best of our knowledge, only one biodegradable alternative has been developed recently by Bone Support $\mathrm{AB}$ (Cerament ${ }^{\mathrm{TM}}$ ), which consists of a mixture of $40 \%$ hydroxyapatite and $60 \%$ of a-calcium sulfate hemihydrate. When mixed with an aqueous solution of a nonionic iodinated aromatic polyol (iohexol), an injectable paste is obtained that hardens in about $15 \mathrm{~min}$ and can be monitored by fluoroscopy. Clinical cases were thus reported for different indications including, vertebroplasty ${ }^{16-19}$ and treatment of aneurysmal bone cyst ${ }^{20}$ or benign bone tumours, ${ }^{21}$ but no detailed physical-chemical characterization of the product was however given. In the present article, an injectable purely apatitic CPC was combined with a water-soluble contrast agent commonly used in angiography (iobitridol, available as Xenetix ${ }^{\vee}$ at the Guerbet company), in order to develop a radiopaque composition suitable for X-ray fluoroscopy-guided implantation in bone. The influence of Xenetix on the setting time, mechanical properties, chemical transformation and microstructure of the resulting composite was investigated, as well as the kinetics of the contrast agent release from the $\mathrm{CPC}$, under conditions simulating in vivo implantation. A small animal model (rat) was used to implant the composite in bone defects to evaluate its local bone tolerance. Finally, CPC formulations loaded with various amounts of Xenetix were implanted in human cadaveric vertebrae, under conditions similar to image-guided vertebroplasty, to determine the optimal loading of radiopaque agent to reach performances as good as the PMMA gold standard, as regards the injectability, texture, and radiopacity of the CPC.

\section{MATERIALS AND METHODS}

Calcium phosphate cement formulations

The apatitic calcium phosphate cement (CPC) used in this study, abbreviated as MIADROS, was obtained from Graftys SA (Aix-en-Provence, France). MIADROS is mainly composed of a mixture of $78 \mathrm{wt} \%$ alpha-tricalcium phosphate ( $a$-TCP) $\left(\mathrm{Ca}_{3}\left(\mathrm{PO}_{4}\right)_{2}\right), 5 \mathrm{wt} \%$ dicalcium phosphate dihydrate (DCPD) ( $\left.\mathrm{CaHPO}_{4}-2 \mathrm{H}_{2} \mathrm{O}\right), 5$ wt \% monocalcium phosphate monohydrate (MCPM) $\left(\mathrm{Ca}\left(\mathrm{H}_{2} \mathrm{PO}_{4}\right)_{2}-\mathrm{H}_{2} \mathrm{O}\right), 10$ wt \% calcium deficient apatite (CDA) (Ca102x [ ] ${ }\left(\mathrm{HPO}_{4}\right)_{\mathrm{y}}\left(\mathrm{PO}_{4}\right)_{62 \mathrm{y}}(\mathrm{OH})_{22 \mathrm{z}}[\mathrm{z}), 2$ wt \% hydroxypropyl methyl cellulose. The liquid phase consists of a 5 wt $\% \mathrm{Na}_{2} \mathrm{HPO}_{4}$ aqueous solution (liquid/powder ratio $50.4 \mathrm{~mL} \mathrm{~g}^{21}$ ). Xenetix 350 was obtained from Guerbet (Villepinte, France) as $20 \mathrm{~mL}$ sealed glass vials with a $350 \mathrm{mg} \mathrm{mL}{ }^{21}$ iodine content. The MIADROS cement paste samples were prepared by mixing the powder mixture with the liquid phase until reaching homogeneity of the obtained paste (i.e., $2 \mathrm{~min}$ ). The same conditions were applied for the preparation of the CPC loaded with the radiopaque agent, except that the liquid phase was partially replaced by Xenetix 350 (see Table I).

\section{Methods}

The high frequency impedance measurements were recorded, between 0.4 and $100 \mathrm{MHz}$, with a HP 4194A impedance/gain-phase analyzer (Hewlett-Packard), using an experimental setup allowing to concomitantly perform complex impedance and Gillmore needles measurements at $378 \mathrm{C}$, as reported previously. ${ }^{22}$

The experimental device was completed by a computer allowing automatic data acquisition and real-time calculation of the complex impedance, $Z^{*}$ from which the dielectric permittivity, $\mathrm{E}^{0}$ (related to dipole variation), and dielectric losses, $\mathrm{E}^{00}$ (related to the motion of free charges), were computed. 23 
The initial setting time $\left(t_{i}\right)$ is defined as the time elapsed until the small Gillmore needle ${ }^{24}$ (diameter $2.12 \mathrm{~mm}$, weight $113.4 \mathrm{~g}$ ) fails to indent the surface of the sample, while the final setting time $\left(t_{f}\right)$ is the corresponding value when using the large Gillmore needle (diameter $1.06 \mathrm{~mm}$, weight $453.6 \mathrm{~g}$ )

All NMR experiments were performed after quenching the cement hydration process by grounding the samples in acetone. The ${ }^{31} \mathrm{P}$ magic angle spinning (MAS) NMR spectra were recorded on a Bruker Advance I spectrometer operating at $7.0 \mathrm{~T}\left({ }^{1} \mathrm{H}\right.$ and ${ }^{31} \mathrm{P}$ Larmor frequencies of 300 and 121.5 MHz, respectively). ${ }^{13} \mathrm{C}$ MAS NMR experiments were conducted on a Bruker Advance III spectrometer operating at $9.4 \mathrm{~T}\left({ }^{1} \mathrm{H}\right.$ and ${ }^{13} \mathrm{C}$ Larmor frequencies of 400 and 100.6 $\mathrm{MHz}$ ). All experiments were performed with a $4 \mathrm{~mm}$ doubleresonance MAS probe head with a spinning fre- quency of 12 $\mathrm{kHz}$ and ${ }^{1} \mathrm{H}$ SPINAL-6425 decoupling with a nutation frequency of $70 \mathrm{kHz}$ was applied during signal acquisition. The ${ }^{31} \mathrm{P}$ quantitative MAS spectra were recorded using a flip angle of 248 (pulse length of $1 \mathrm{~ms}$ ) and 128 scans were coadded with a recycle delay of $60 \mathrm{~s}$ to ensure complete recovering of the longitudinal magnetization. The ${ }^{13} \mathrm{C}-\left\{{ }^{1} \mathrm{H}\right\}$ CP-MAS spectra were acquired using a contact time of $1 \mathrm{~ms}$, with a linear amplitude ramp ${ }^{26}$ on the ${ }^{1} \mathrm{H}$ channel and a recycle delay of $1 \mathrm{~s}$. Approximately 63,000 transients were coadded for pure iobitridol in its solid form and the CPC loaded with Xenetix (56 mg I mL ${ }^{21}$ ) (experiment dura tion of about $18 \mathrm{~h}$ ), while 235,000 scans were recorded for

the MIADROS CPC reference (experiment duration of about $65 \mathrm{~h}) .{ }^{31} \mathrm{P}$ and ${ }^{13} \mathrm{C}$ chemical shifts were referenced relative to $\mathrm{H}_{3} \mathrm{PO}_{4} 85 \%$ and TMS, respectively.

In order to follow ex situ the progressive transformation of $a$-TCP to CDA, the quantitative ${ }^{31} \mathrm{P}$ MAS spectra were reconstructed with the Dmfit program ${ }^{27}$ using four independent contributions, three of them corresponding to the ${ }^{31} \mathrm{P}$ experimental spectra of $a$-TCP, DCPA, and DCPD, and the remaining one being a Lorentzian line centered at approximately $2.9 \mathrm{ppm}$ characteristic of the CDA phase. The relative amount (in wt \%) of each phase as a function of the setting time was determined assuming that the composition of the formed CDA phase was close to $\mathrm{Ca}_{9}\left(\mathrm{HPO}_{4}\right)\left(\mathrm{PO}_{4}\right)_{5} \mathrm{OH}$.

Scanning electron microscope (SEM) observation of the cement samples was performed using a field emission gun scanning electron microscope (Jeol 7600F). Images were acquired on back scattered electron mode with a $9 \mathrm{pA}$ beam current and a $10 \mathrm{kV}$ accelerated voltage. A $1 \mathrm{~mm}^{2}$ polished cross-section of the cement samples was obtained using a JEOL cross section polisher SM09010, by applying an argon ion beam accelerated by a voltage up to $6 \mathrm{kV}$ perpendicular to the surface of each specimen for $6 \mathrm{~h}$.

Compressive strength measurements and texture analyses versus time were performed using a AMETEK LS5 texture analyzer.

In vitro monitoring of the iobitridol release from CPCs Hydrodynamic conditions. A glass column $(6.6 \mathrm{~mm}$ in diameter) fitted with a PE filter was filled with a weighed quantity (ca. 5 g) of cement paste loaded with Xenetix, with an iodine concentration of $56 \mathrm{mg} \mathrm{I} \mathrm{mL}^{21}$ in the sample. The CPC was allowed to set for 7 days at $378 \mathrm{C}$ in a humid chamber, by immersing the entire column in a 0.9 wt $\%$ sodium chloride aqueous solution $(\mathrm{NaCl})$, which was replaced every 2-3 days. Percolation of a $0.9 \mathrm{wt} \%$ sodium chloride aqueous solution through the column was then performed using a high-pressure pump (Gilson 307), to control the flow rate. The eluted solution was collected in tared vials at the column outlet and weighed. The amount of iobitridol released as a function of the percolated volume was measured by UV-visible, using a Shimadzu UV-2501PC spectrometer. Quantification was made at the wavelength of maximum absorption of iobitridol ( $\mathrm{k}_{\max } 5243 \mathrm{~nm}$ ). A calibration curve in the $0-0.035 \mathrm{mg} \mathrm{I} \mathrm{mL}{ }^{21}$ range was recorded prior to the experiments by dilution of a galenic Xenetix solution (350 mg I mL 21 iodine content) in pure water. Two columns were prepared under similar conditions, to ensure of the repeatability of the method.

Batch conditions. Cement samples loaded with Xenetix (56 mg I mL ${ }^{21}$ ), prepared as described above, were directly introduced into PTFE molds (inner diameter: $6 \mathrm{~mm}$; height $12 \mathrm{~mm}$ ), that were weighed and placed after $30 \mathrm{~min}$ in a known volume of 0.9 wt \% sodium chloride aqueous solution for $24 \mathrm{~h}$. The amount of iobitridol desorbed during this step was measured by UV-vis spectroscopy. Then the obtained hardened CPC blocks were taken out of the mold, weighed and then placed in individual beakers that were hermetically sealed to prevent evaporation. A 0.9 wt \% sodium chloride aqueous solution was used as desorption medium. Different liquid to solid ratios were investigated, with regular renewal of the solution (for details, see Figure

3) and the determination of the iobitridol content in the successive baths was again carried out by UV-vis spectroscopy.

In vivo evaluation of the local bone tolerance of iobitridol-loaded CPCs

All animal handling and surgical procedures were conducted according to European Community guidelines for the care and use of laboratory animals (DE 86/609/CEE). The study was approved by the local ethical committee for animal experimentation.

The animals (14 male Lewis rats aged 14 weeks, and weighing approximately $350 \mathrm{~g}$ ) were placed in quarantine for at least 10 days prior to surgery. General anesthesia was performed using an intramuscular injection of ketamine and xylazine. The animals were surgically prepared by shaving both lower limbs, skin disinfection with iodine solution and sterile draping. A longitudinal skin incision $(1.5 \mathrm{~cm})$ was made to expose the distal lateral femoral condyle. A large size defect of $2.7 \mathrm{~mm}$ in diameter and $3 \mathrm{~mm}$ in depth was created at the epiphyseal-metaphyseal junction by using a motor-driven driller. The drilling process was achieved in three successive steps using burs of $1.5,2$, and $2.7 \mathrm{~mm}$ in diameter. During the drilling process, the defect site was continuously irrigated using a syringe of sterile saline solution. Bone chips and particles were removed from the defects by irrigation with saline solution. The defects were 
<smiles>CN(CC(O)CO)C(=O)c1c(I)c(NC(=O)C(CO)CO)c(I)c(C(=O)N(C)CC(O)CO)c1I</smiles>

FIGURE 1. Chemical formula of iobitridol.

then packed with sterile swabs and ribbon gauzes until bleeding had subsided. The femoral cavities were then filled with about $0.6-0.7 \mathrm{~g}$ of the selected cement composition, that is, loaded with various amounts of Xenetix $(0,37,56$, and $80 \mathrm{mg} \mathrm{I} \mathrm{mL}^{21}$ of cement paste, respectively). The subcutaneous tissues and skin were closed in different layers using degradable sutures. The surgical site was finally covered with an adhesive bandage. Postoperative radiographic monitoring of the animals (Faxitron, $9.5 \mathrm{~s}, 35 \mathrm{kV}$ ) was performed at day $0,7,14$, and 28 , and the rats were sacrificed at day 28 by $\mathrm{CO}_{2}$ inhalation for histological analysis of the implanted area.

For that purpose, bone explants were fixed by immersion into $10 \%$ formol for 2 days, then decalcified in a $10 \mathrm{wt}$ $\%$ ethylenediaminetetraacetic acid solution for 3 weeks, and finally embedded into paraffin. The resulting samples were cut into $4 \mathrm{~mm}$ thin slices from which paraffin was removed using xylene, before hematoxylin-eosin-safran staining. Histological analysis was carried out using an Axioskop Zeiss microscope equipped with a digital camera, and the image processing was run using the Axio Vision (Zeiss) software.

Image-guided implantation of iobitridol-loaded CPCs in human cadaveric vertebra

This study was performed in the Radiology and Medical Imaging Department of the Sainte Marguerite Hospital in Marseille. Injection of the CPC formulations was performed under classical PMMA vertebroplasty conditions, by two interventional radiologists with, respectively, 10 and 5 years of experience in this procedure.

For the first part of the experiment, four humid human cadaveric vertebrae blocks from two donors were used and placed in a plastic dummy stuffed with polyurethane to mimic soft tissues. For each injected vertebra, one individual syringe of CPC was prepared and the operators were asked to inject the necessary volume to fill the vertebra. The amount of radiopaque agent introduced in the CPC formulation was adjusted through partial replacement of the liquid phase ( $5 \mathrm{wt} \% \mathrm{Na}_{2} \mathrm{HPO}_{4}$ ) by the appropriate volume of sterile Xenetix 350, while keeping all other parameters fixed. After preparation of each dose of cement ( $6 \mathrm{~g}$ of powder $12.4 \mathrm{~mL}$ of liquid, leading to a cement paste containing $0,37,47,56$, or $70 \mathrm{mg} \mathrm{I} \mathrm{mL}{ }^{21}$, respectively), the resulting paste was immediately transferred into an injector (Somatex ${ }^{\Downarrow} \mathrm{mL}-$ ref 180710 ) that was then connected to a trocart (Optimed ${ }^{\Downarrow} 10$ gauge, $0.7 \mathrm{~mL}$-ref 1394-1010), before injection of the cement paste under fluoroscopy (Philips ALLURA FD20). The injections were performed under blind conditions (i.e., the two operators did not know the Xenetix content in the injected formulations), and for each vertebra, a rating of the radiopacity, injectability and texture of the CPC was given by the operating interventional radiologist, in comparison with standard PMMA used for vertebroplasty (see below).

\begin{tabular}{llll}
\hline Rating & Radiopacity & Injectability & \multicolumn{1}{c}{ Texture } \\
\hline 1 & Insufficient & Difficult & Too liquid/thick \\
2 & Limited & Uncomfortable & Fair \\
3 & Satisfactory & Satisfactory & Satisfactory \\
4 & Optimal & Comfortable & Optimal \\
\hline
\end{tabular}

In accordance with local ethics and safety regulations, three female human cadavers with distinct body mass index (BMI) were selected for the second part or the experiment: specimen 1 (83 years old, average BMI ;:: 23), specimen 2 (92 years old, high BMI ;:: 30), and specimen 3 (84 years old, low BMI ;:: 18). A strictly similar protocol was used by the same two operators, assisted by a fellow in interventional radiology as third operator, for the image-guided injection of the CPC (one unique loading of radiopaque agent, corresponding to a cement paste containing $56 \mathrm{mg} \mathrm{I}$ $\mathrm{mL}^{21}$ ), except that a less performing fluoroscope was employed (STENOSCOP2 General Electric CGR).

\section{RESULTS}

In the present study, we have introduced a water-soluble iodinated contrast agent into the composition of an injectable purely apatitic cement currently developed by Graftys for the prevention of the secondary fracture of the proximal femur in osteoporotic patients [abbreviated as MIADROS]. Iobitridol (Xenetix-Figure 1), a non-ionic low-osmolality iodinated contrast agent, was selected because it is one of the gold standards for radiographical examination with $>20$ years of experience since it was first launched in 1994. To facilitate the preparation of sterile samples, the liquid phase (5 wt \% $\mathrm{Na}_{2} \mathrm{HPO}_{4}$ ) was partially replaced by the sterile galenic form (350 $\mathrm{mg}$ iodine per $\mathrm{mL}$ ) of the radiopaque agent, while keeping all other parameters fixed. Various amounts of Xenetix were loaded in the CPC formulation, in order to (i) investigate whether the presence of the contrast agent might influence the general properties of the CPC and (ii) determine the minimal dose for appropriate visualization of the product under X-ray imaging conditions.

Influence of the contrast agent on the setting time and mechanical properties

The Gillmore needles standard test method was used to investigate the influence of the addition of increasing amounts of Xenetix 350 (up to $80 \mathrm{mg}$ of iodine per $\mathrm{mL}$ of cement paste) on the CPC setting reaction at body temperature. Based on a change in the material's penetration resistance, the initial setting time $\left(t_{\mathrm{i}}\right)$ was measured, showing 

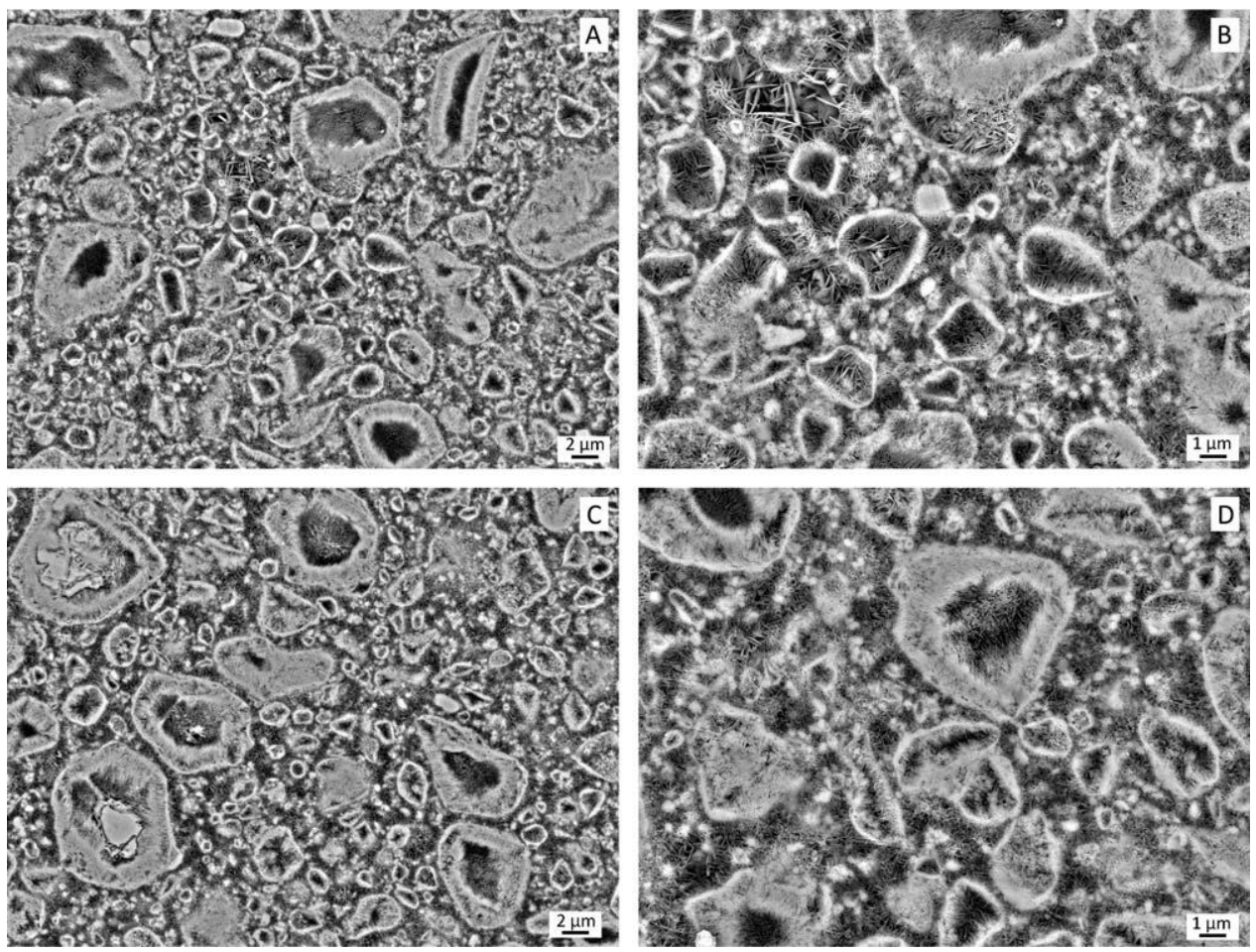

FIGURE 2. SEM observations of a polished cross-section of a radiopaque agent free MIADROS sample (bottom views; magnification: 32500 (C) and 35000 (D)) and its analogue loaded with Xenetix (56 mg I mL $2^{1}$-top views; magnification: 32500 (A) and 35000 (B)), after a setting time of $72 \mathrm{~h}$.

very similar results, except for the higher dose for which a significant augmentation of the setting time was observed (Table I). This is very likely related to a decrease of the phosphate concentration in the liquid phase upon partial replacement of the phosphate buffer by Xenetix, which is known to slow down the CPC setting reaction. We have recently reported ${ }^{22}$ that high frequency impedance measurements can be used to monitor the $a$-TCP to calciumdeficient hydroxyapatite (CDA) transformation occurring during the setting process of CPCs, in particular in the presence of additives which can influence this reaction. When conversion of $a$-TCP into CDA starts, an increase in the dielectric permittivity $\left(\mathrm{E}^{0}\right)$ is thus observed, in relation with the accumulation of mobile nonbonded charged species on the surface of the solid reactants and the formation of a supersaturated medium. At the same time, a sharp decrease of the dielectric losses $\left(\mathrm{E}^{00}\right)$ takes place as a result of the precipitation of CDA crystals in the intergranular space as well as on the surface of $a$-TCP particles. For increasing amounts of Xenetix in the CPC composition up to $70 \mathrm{mg} \mathrm{I}$ $\mathrm{mL}^{21}$, experimental data (see Figure S1 in Supporting Information) show that evolution of the $\mathrm{E}^{0}$ and $\mathrm{E}^{00}$ parameters has already started (i.e., $6 \mathrm{~min}$ are necessary to prepare the cement paste and load it in the dielectric cell before recording the first measurable dielectric values). In addition, the radiopaque agent does not inhibit or delay the setting reaction. Then, the hydrolysis of $a$-TCP into CDA propagates from the surface to the inner part of the particles and an attenuation of the variation of the $\mathrm{E}^{0}$ and $\mathrm{E}^{00}$ parameters is therefore observed, before slow stabilization after about 25$30 \mathrm{~min}$ for the Xenetix-containing formulations, as compared to about $15 \mathrm{~min}$ for the CPC reference (Figure S1). Ex situ ${ }^{31}$ P MAS NMR analyses of the amount of $a$-TCP transformed into CDA after an ageing period of $6 \mathrm{~h}, 3$ days, and 2 weeks, respectively, showed no significant difference between the radiopaque agent free CPC and its analog loaded with Xenetix (56 mg I mL ${ }^{21}$ ), thus confirming that the setting reaction is not significantly influenced by the presence of the radiopaque agent in the CPC (Table I; see also Figure S2).

Moreover, the introduction of Xenetix into the CPC composition did not result in significant changes in the mechanical properties of the resulting composite (see Table I), since the compressive strength after a setting time of $72 \mathrm{~h}$ was in the similar range in the presence (22 $62 \mathrm{MPa}$ ) or absence (19-20 $62 \mathrm{MPa}$ ) of Xenetix, except for the higher dose for which the cement paste was not cohesive anymore, leading to a decrease of the mechanical properties.

Influence of the contrast agent on the microstructure of hardened cements

In order to investigate whether the presence of the radiopaque agent in the CPC formulation might influence the microstructure of the hardened cement, SEM observations were performed on polished cross-sections of the radiopaque agent free CPC and its analogue loaded with a median dose of Xenetix (i.e., 56 mg I mL ${ }^{21}$ ). 


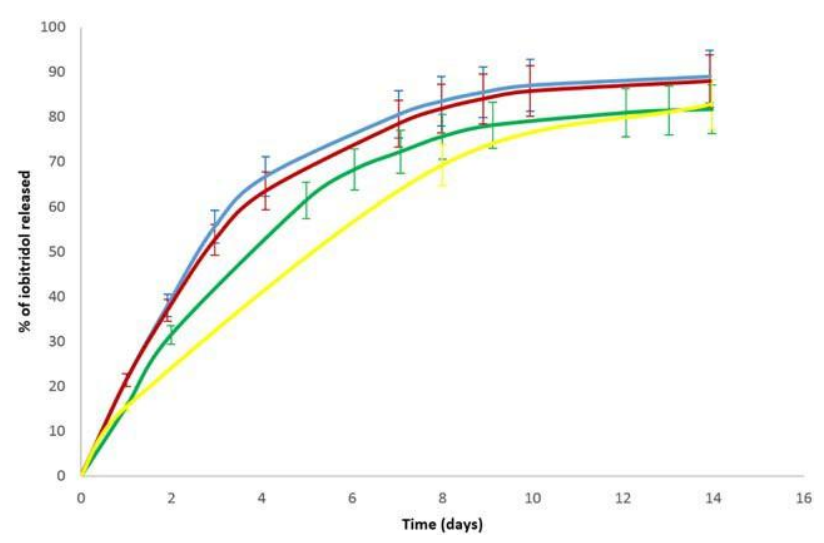

FIGURE 3. Amount of iobitridol desorbed from cement blocks loaded with Xenetix (56 mg I $\mathrm{mL}^{2}{ }^{1}$ ), as a function of time. Desorption solution: 0.9 wt $\%$ sodium chloride aqueous solution at $378 \mathrm{C}$. Blue curve: $\mathrm{S} / \mathrm{L} 50.06 \mathrm{~g} \mathrm{~mL}^{2}$ (eight renewals of the desorption solution); red curve: $\mathrm{S} / \mathrm{L} 50.12 \mathrm{~g} \mathrm{~mL}^{1}$ (eight renewals of the desorption solution); green curve: $\mathrm{S} / \mathrm{L} 50.25 \mathrm{~g} \mathrm{~mL}^{2}$ (nine renewals of the desorption solution); yellow curve: $\mathrm{S} / \mathrm{L} 50.25 \mathrm{~g} \mathrm{~mL}^{2}$ (two renewals of the desorption solution). Note that for $\mathrm{S} / \mathrm{L} 50.12 \mathrm{~g} \mathrm{~mL}^{2}$, with no renewal of the desorption medium, the iobitridol release after 2 months was $88(66) \%$.

In the case of the MIADROS composition, a large amount of geode-like particles can be observed, showing a dense shell lined in its inner part with entangled needle-shaped crystals, consistent with a complete hydrolysis of $a$-TCP into CDA (bottom right view in Figure 2). However, hydrolysis is only partial for larger $a$-TCP particles (bottom left view in Figure 2), while a few DCPA particles are also present that are dense along their whole cross-section. Finally, the area in between all these particles is mostly occupied by a rather porous network of platelet-like CDA crystals. When combined with Xenetix, the microstructure of the cement looks fully similar (top views in Figure 2).

Release of the contrast agent under in vitro conditions In order to model the release of the contrast agent from the cement paste under bone implantation conditions, molded blocks ( $6 \mathrm{~mm}$ in diameter and $12 \mathrm{~mm}$ in height) of the CPC loaded with a median dose of Xenetix (i.e., $56 \mathrm{mg} \mathrm{I} \mathrm{mL}{ }^{21}$ ) were immerged in a $0.9 \mathrm{wt} \%$ sodium chloride solution at 378C, under static conditions. The iobitridol concentration in the desorption solution was then measured by UV-vis spectroscopy. Different options were investigated (i.e., solid to liquid ratio [S/L 5 0.06, 0.12, $0.25 \mathrm{~g} \mathrm{~mL}^{21}$, respectively], number of renewals of the sodium chloride solution [2 vs. 8-9]) and the results are summarized in Figure 3. After 2 weeks, about $85(66) \%$ of iobitridol was released from the $\mathrm{CPC}$, with very little influence of the solid to liquid ratio.

The release of iobitridol was then investigated under hydrodynamic conditions, using a glass column filled with a cement paste loaded with Xenetix (56 mg I $\mathrm{mL}^{21}$ ) and allowed to set for 7 days at 378C under humid conditions (see Materials and Methods). Percolation of a 0.9 wt \% sodium chloride aqueous solution was then performed under controlled pressure (around 1-2 bars) resulting in an outlet flow rate close to $10 \mathrm{1L} \min ^{21}$. In addition to the amount of radiopaque agent released during the equilibration time of the column, the iobitridol concentration at the column outlet was then measured, as a function of the percolated volume (Figure 4). The release of iobitridol is very rapid, since about $97(67) \%$ is washed out of the column after a percolated volume of about $75 \mathrm{~mL}$ which corresponds to a time period of about 3 days under these experimental conditions.

In vivo evaluation of the bone local tolerance of CPCs loaded with Xenetix

The radiopaque CPC formulations were implanted in large size cavitary defects created in the distal lateral femoral condyle of rats, to evaluate their local bone tolerance. Each of the 14 animals were implanted on both sides and showed a good recovery after surgery, with comparable weight gain. Radiographic studies gave evidence of a correct filling of the defects with no cement leakage. No fibrous tissue or deleterious effect on surrounding bone marrow was observed upon histological examination of bone explants and the formation of new trabecular bone was present in all conditions. In summary, there was no significant difference in the biological response of iobitridol-loaded CPC by comparison with the radiopaque agent free $\mathrm{CPC}$ control. Moreover, the characteristic process involved in the CPC remodeling similarly occurred, whatever the amount of Xenetix present in the cement paste $\left(0,37,56\right.$, and $80 \mathrm{mg} \mathrm{I} \mathrm{mL}{ }^{21}$-see Figure S4).

Assessment of the potential of radiopaque CPCs for their image-guided implantation

A first experiment was designed to assess the safety of a vertebroplasty procedure using the CPCs loaded with various amount of Xenetix $\left(0,37,47,56\right.$, and $70 \mathrm{mg} \mathrm{I} \mathrm{mL}{ }^{21}$ of cement paste). For that purpose, the different CPC formulations were injected under fluoroscopy guidance, in humid human cadaveric vertebrae blocks placed in a plastic dummy stuffed with polyurethane to mimic soft tissues (Figure 5). The procedure was performed under blind conditions by two interventional radiologists familiar with PMMA

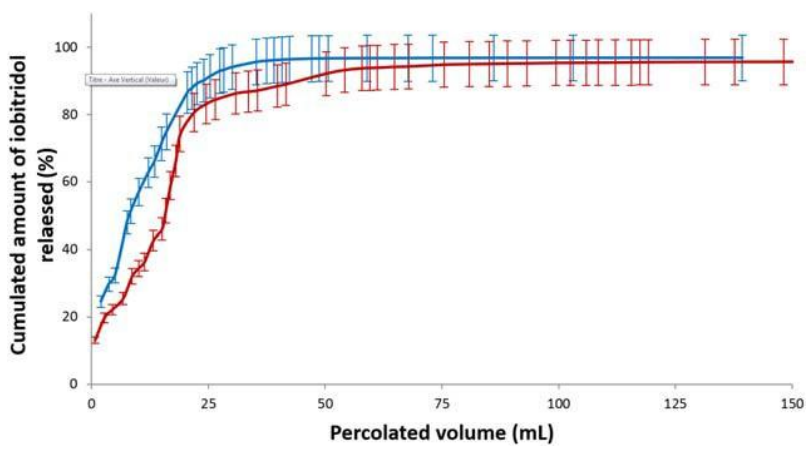

FIGURE 4. Amount of iobitridol desorbed under hydrodynamic conditions from a hardened cement column loaded with Xenetix (56 mg $\left.\mathrm{I} \mathrm{mL}^{2^{1}}\right)$, as a function of the percolated volume. Desorption solution: 0.9 wt $\%$ sodium chloride aqueous solution at $378 \mathrm{C}$. The blue and red curves correspond to two different columns prepared under similar conditions, to ensure of the repeatability of the experiment. 

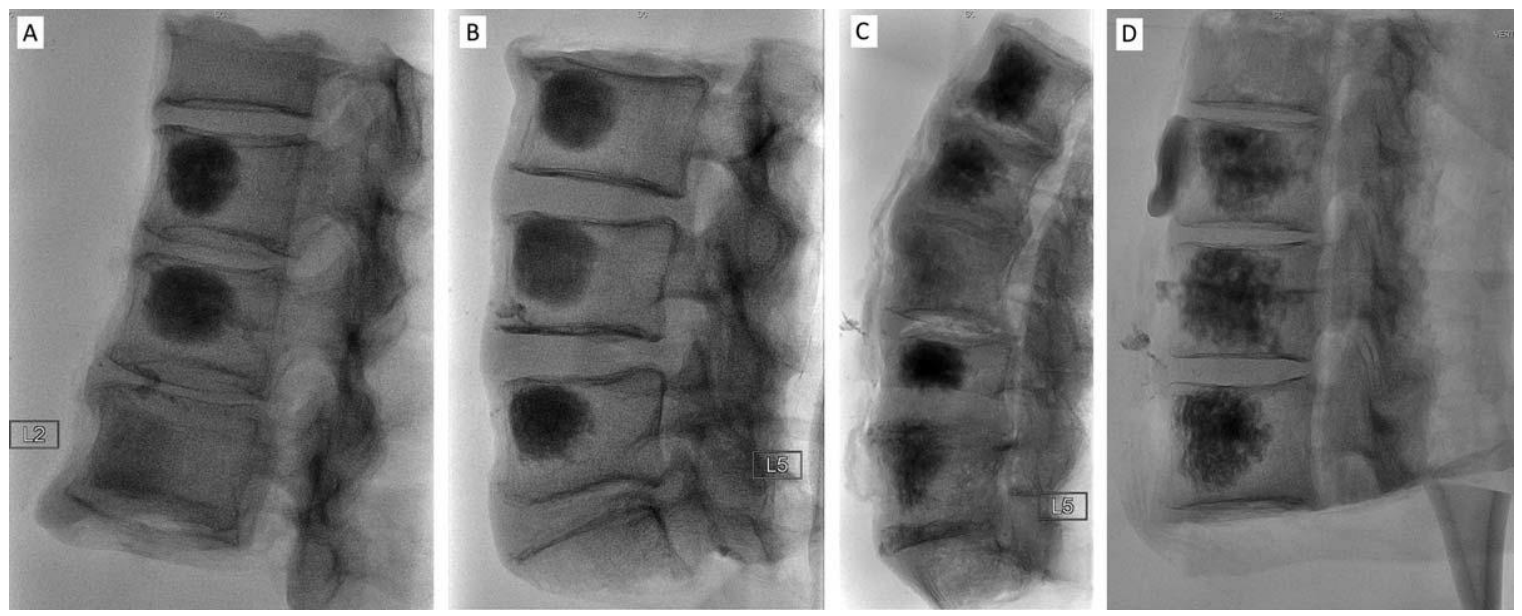

FIGURE 5. Fluoroscopy images of human cadaveric vertebrae blocks after injection of CPCs loaded with various amounts of Xenetix (inje cted

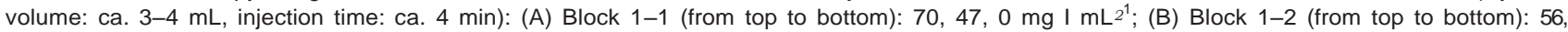
37, $70 \mathrm{mg} \mathrm{I} \mathrm{mL2} 2^{1}$; (C) Block 2-1 (from top to bottom): 56, 37, 0, 70, $47 \mathrm{mg} \mathrm{I} \mathrm{mL} 2^{1}$; (D) Block 2-2 (from top to bottom): $56,56,70 \mathrm{mg} \mathrm{I} \mathrm{mL2}{ }^{1}$.

vertebroplasty, with a rating of the radiopacity, texture and injectability of the five investigated compositions by comparison to PMMA, on a scale ranging from 1 (unsatisfactory) to 4 (excellent), reported in Table II.

The global assessment of the five formulations for the selected criteria (Figure 6) showed that for a loading of Xenetix greater or equal to $56 \mathrm{mg} \mathrm{I} \mathrm{mL}^{21}$ of cement paste, acceptable performances were achieved.

In order to confirm that the $56 \mathrm{mg} \mathrm{I} \mathrm{mL}{ }^{21}$ dosage of the CPC was sufficient for a comfortable visualization of the cement under the typical conditions of vertebroplasty, a second experiment was performed on three female human cadavers of different body mass, using an old generation fluoroscopy equipment available in the surgical room (see Figure S5). The injection was performed by three interventional radiologists, and again the radiopacity, texture, and injectability of the CPC composition were rated on a scale ranging from 1 to 4 , and the results are reported in Table III. For the three operators the radiopacity of the CPC was considered as suitable for the easy monitoring of the injection under fluoroscopy guidance, whatever the body mass of the specimen. However, a leakage out of the vertebrae was systematically observed for specimen 1 and 2, resulting in a low rating of the texture (2 or 3). Interestingly, when the time elapsed between the preparation of the cement paste and the start of the injection was longer than $11 \mathrm{~min}$ (Table III, specimen 3), no more leakage occurred, with no detrimental effect on the injectability.

\section{DISCUSSION}

PMMA is currently the gold standard material for the vertebroplasty/kyphoplasty-mediated management of acute

TABLE II. Assessment of the Radiopacity, Texture, and Injectability of CPCs Loaded with Various Amounts of Xenetix (0, 37, 47, 56, and $70 \mathrm{mg} \mathrm{I} \mathrm{mL}^{21}$ of Cement Paste) and Injected in Humid Human Cadaveric Vertebrae Blocks

\begin{tabular}{|c|c|c|c|c|c|c|c|c|c|}
\hline \multirow[b]{2}{*}{ Specimen } & \multirow[b]{2}{*}{$\begin{array}{c}\text { Vertebra } \\
\text { Block }\end{array}$} & \multirow[b]{2}{*}{ Vertebra } & \multirow{2}{*}{$\begin{array}{l}\text { Xenetix } \\
\text { Loading } \\
\text { (mg I/mL) }\end{array}$} & \multicolumn{2}{|c|}{ Radiopacity Rating } & \multicolumn{2}{|c|}{ Injectability Rating } & \multicolumn{2}{|c|}{ Texture Rating } \\
\hline & & & & Operator A & Operator B & Operator & A Operator B & Operator A & Operator B \\
\hline \multirow[t]{4}{*}{ B) } & & L1 & 47 & 2 & 3 & na & 3 & na & 3 \\
\hline & & L2 & 0 & 1 & 1 & na & 1 & na & 1 \\
\hline & $1-2$ & L3 & 56 & 3 & 31 & na & 4 & na & 4 \\
\hline & & L5 & 70 & 3 & 31 & na & 3 & na & 31 \\
\hline 2 (operator & $2-1$ & L1 & 56 & 21 & 3- & 2 & na & 3 & na \\
\hline \multirow[t]{6}{*}{ A) } & & L2 & 37 & 2 & 2 & 3 & na & 3 & na \\
\hline & & L3 & 0 & 1 & 1 & 2 & na & 2 & na \\
\hline & & L4 & 70 & 3 & 4 & 3 & na & 3 & na \\
\hline & & L5 & 47 & 2 & 3- & 2 & na & 3 & na \\
\hline & $2-2$ & T10 & 56 & 3 & 31 & 3 & na & 3 & na \\
\hline & & T12 & 70 & 3 & 31 & 3 & na & 4 & na \\
\hline
\end{tabular}

${ }^{a}$ Experiments were run under blind conditions and the rating of the selected criteria was made on a scale ranging from 1 (unsatisfactory) to 4 (excellent). For each vertebra, one individual syringe of CPC was prepared. Note that the radiopacity assessment could be made by the two operators who were both present during the whole experiment.

${ }^{\mathrm{b}}$ na, not applicable. 


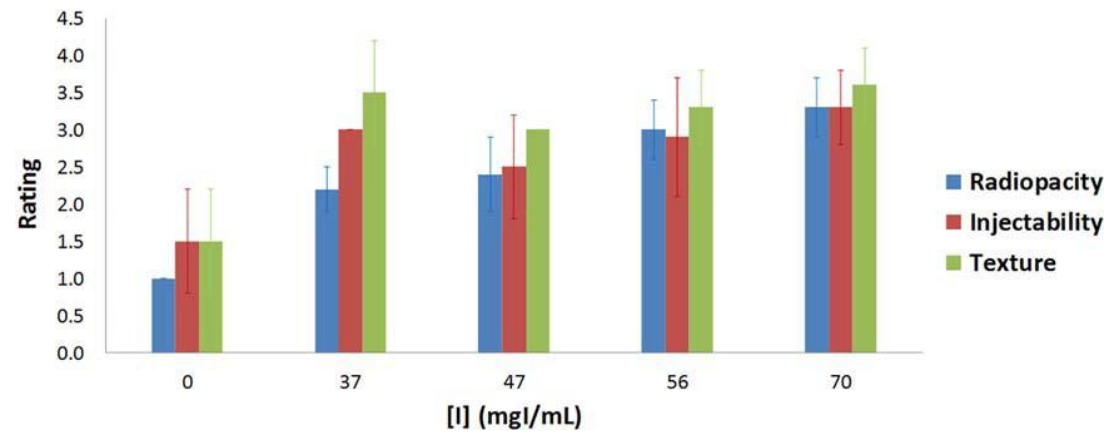

FIGURE 6. Global assessment of the CPCs loaded with various amounts of Xenetix $\left(0,37,47,56\right.$, and $70 \mathrm{mg} \mathrm{I} \mathrm{mL} 2^{1}$ of cement paste- $\mathrm{x}$-axis), on the basis of radiopacity, texture and injectability criteria. The rating ( $y$-axis) was made on a scale ranging from 1 (unsatisfactory) to 4 (excellent).

vertebral compression fractures, for the treatment of pain. Since the vertebral augmentation procedure is conducted under image-guided conditions, ${ }^{28-42}$ the injectable PMMA resin contains barium sulfate particles to enhance its radiopacity and allow appropriate visualization of the product during its injection into the fractured vertebral body. However, barium sulfate which is hardly soluble in aqueous media, cannot be used for the preparation of radiopaque CPCs, since the gradual resorption of the CPC would result in the release of solid particles in the blood stream. Therefore, an aromatic iodinated water soluble contrast agent was selected for this study, in an attempt to prepare injectable radiopaque apatitic CPC formulations. Replacement of part of the liquid phase of the CPC by Xenetix (iobitridol, Figure 1), a liquid contrast agent commonly used for angiography, led to CPC formulations compatible with their surgical use. Indeed, for an iodine content in the cement paste up to $70 \mathrm{mg} \mathrm{I} \mathrm{mL}^{21}$, no significant difference could be observed with respect to the undoped CPC analogue, in terms of setting time, compression strength, or transformation kinetics of $a$-TCP into CDA (Table I). In addition, the final microstructure of the CPC once hardened, assessed by SEM observation of polished cross-sections of the samples, was found to be similar in the absence or presence of
Xenetix. On the other hand, the release of iobitridol from hardened cement blocks was monitored under static and hydrodynamic conditions in a 0.9 wt \% sodium chloride solution at $378 \mathrm{C}$, to investigate whether the contrast agent is irreversibly trapped or not during the setting process. In both conditions, the most part of the radiopaque agent was released quite rapidly, giving evidence that (i) the interaction of iobitridol with the inorganic apatitic network is very limited, (ii) the permeability of the CPC once hardened is high enough to allow iobitridol to diffuse out of the bone substitute quite rapidly. As a consequence, the quick release of the contrast agent makes long-term follow-up of the cement impossible. However, this potential drawback might be compensated by the fact that the risk of chronic adverse effects upon implantation of the developed radiopaque CPC should be limited. Furthermore, histological analysis of bone explants clearly evidenced a similar biological response for iobitridol-loaded CPCs and the unloaded CPC control, with no incidence of the radiopaque agent on the CPC remodeling process.

To evaluate the potential of Xenetix-containing CPCs for vertebroplasty procedures, CPC loaded with different doses of radiopaque agent have been implanted in humid human cadaveric vertebrae blocks, by interventional radiologists

TABLE III. Assessment of the Radiopacity, Texture, and Injectability of a CPC Loaded with Xenetix (56 mg I mL $\mathrm{m}^{\text {l' }}$ of Cement Paste) and Injected in Vertebrae of Human Cadavers (Injected Volume: ca. 3-5 mL)

\begin{tabular}{|c|c|c|c|c|c|c|}
\hline Specimen & Operator & Vertebra & $t_{0}\left[t_{1}\right]$ & Radiopacity Rating & Injectability Rating & Texture Rating \\
\hline \multirow[t]{5}{*}{1} & $A$ & L5 & $3.5[6.5]$ & 3 & 3 & 2 \\
\hline & & $\mathrm{T} 10$ & $3.5[5.5]$ & 3 & 3 & 2 \\
\hline & & $\mathrm{T} 12$ & $4[5.8]$ & 3 & 3 & 2 \\
\hline & & L2 & $4[5.9]$ & 3 & 3 & 2 \\
\hline & & L4 & $4.6[5.2]$ & 3 & 3 & 2 \\
\hline \multirow[t]{4}{*}{2} & B & T9 & $5[6]$ & 4 & 4 & 3 \\
\hline & & $\mathrm{T} 11$ & $6[7]$ & 4 & 4 & 3 \\
\hline & & L1 & $6.5[7.5]$ & 4 & 4 & 3 \\
\hline & & L3 & $7[8.3]$ & 4 & 4 & 3 \\
\hline \multirow[t]{4}{*}{3} & $\mathrm{C}$ & L4 & 9 [11.1] & 4 & 4 & 3 \\
\hline & & L3 & $11[12.5]$ & 4 & 4 & 4 \\
\hline & & $\mathrm{T} 12$ & $11[11.7]$ & 4 & 4 & 4 \\
\hline & & $\mathrm{T} 11$ & $11[11.7]$ & 4 & 4 & 4 \\
\hline
\end{tabular}

\footnotetext{
a The rating of the selected criteria was made on a scale ranging from 1 (unsatisfactory) to 4 (excellent). $t_{0}$ (in minutes) corresponds to the time elapsed between the preparation of the cement paste and the start of the injection; $t_{1}$ (in minutes) corresponds to the time elapsed between the preparation of the cement paste and the end of the injection. For each vertebra, one individual syringe of CPC was prepared.
} 
following an image-guided procedure performed thanks to classical fluoroscopy equipments used in osteoarticular radiology, having a resolution (pixel size) in the $0.1-0.2 \mathrm{~mm}$ range. This investigation was conducted under blind conditions, to determine whether some of the investigated compositions gave results comparable to the PMMA standard, in terms of injectability, texture, and radiopacity. This was effectively the case when the cement paste contained at least $56 \mathrm{mg} \mathrm{I} \mathrm{mL}^{21}$. A second similar experiment was then performed to confirm that the $56 \mathrm{mg}$ I $\mathrm{mL}^{21}$ minimal dose was appropriate, except that the surgery was directly performed on three female human cadavers. While the radiopacity was again found to be suitable for a comfortable visualization of the product, we have found that the texture of the composite is advantageously improved when a waiting time of about $10 \mathrm{~min}$ before injection is applied right after the preparation of the cement paste. Such conditions allowed to prevent any leakage phenomena, while still retaining good injectability of the product.

\section{CONCLUSION}

In this article, an injectable purely apatitic calcium phosphate cement was successfully combined to Xenetix, a nonionic water-soluble iodinated contrast agent. For a final iodine concentration in the cement paste up to $70 \mathrm{mg}$ I $\mathrm{mL}^{21}$, the main general properties of the resulting composite were retained, as regards the injectability, cohesion, and setting time. Moreover, when hardened, similar microstructure, mechanical strength and $a$-TCP to CDA transformation were observed, regardless of whether or not Xenetix was present in the CPC formulation. In vivo implantation of Xenetix-containing CPC in bone large size defects gave evidence that the radiopaque cement was fully tolerated, with no adverse effect resulting from the presence of the contrast agent. Moreover, all Xenetix-containing CPCs exhibited a rapid and nearly quantitative release of the contrast agent. All together, these data demonstrate that Xenetix-containing CPCs are compatible for a surgical use. Moreover, their implantation in human cadaveric vertebrae was performed under image-guided procedure, to determine the minimal Xenetix dosage in the cement paste to allow comfortable visualization of the material during surgery. Hence, a $56 \mathrm{mg}$ I $\mathrm{mL}^{21}$ content in the cement paste was found to be appropriate, and suitable conditions for the preparation of the cement paste before injection were found, leading to a behavior during the implantation procedure that was considered by the interventional radiologists as satisfactory as with PMMA formulations used for vertebroplasty. Complementary studies are underway to investigate the potential of the radiopaque CPC developed in this work for indications for which minimally invasive image-guided implantation of injectable CPCs might represent an added value.

\section{ACKNOWLEDGMENTS}

The authors greatly acknowledge the Scanning Electron Microscopy facility at the Institut des Materiaux Jean Rouxel laboratory, and particularly Nicolas Stephant for his technical support.

\section{DISCLOSURE}

Some authors of this publication have research support from Graftys SA. The terms of this arrangement have been reviewed and approved by both CNRS and the University of Nantes in accordance with their policy on objectivity in research.

\section{REFERENCES}

1. Ambrosio L, Guarino V, Sanginario V, Torricelli P, Fini M, Ginebra MP, Planell JA, Giardino R. Injectable calcium-phosphate-based composites for skeletal bone treatments. Biomed Mater 2012;7: 024113.

2. Bohner M, Gbureck U, Barralet JE. Technological issues for the development of more efficient calcium phosphate bone cements: A critical assessment. Biomaterials 2005;26:6423-6429.

3. Brown WE, Chow LC. A new calcium phosphate setting cement. J Dent Res 1983;62:672-679.

4. Dorozhkin SV. Calcium orthophosphate cements for biomedical application. J Mater Sci 2008;43:3028-3057.

5. Dorozhkin SV. Calcium orthophosphate cements and concretes. Materials 2009;2:221-291.

6. Dorozhkin SV. Self-setting calcium orthophosphate formulations. J Funct Biomater 2013;4:209-311.

7. LeGeros R, Chohayeb A, Shulman A. Apatitic calcium phosphates: Possible restorative materials. J Dent Res 1982;61 (Special Issue): 343.

8. Graftys. https://clinicaltrialsgov/ct2/show/study/NCT02575352.

9. Ollivier M, Gay AM, Cerlier A, Lunebourg A, Argenson JN, Parratte S. Can we achieve bone healing using the diamond concept without bone grafting for recalcitrant tibial nonunions? Injury 2015;46:1383-1388.

10. Ollivier M, Turati M, Munier M, Lunebourg A, Argenson J-N, Parratte S. Balloon tibioplasty for reduction of depressed tibial plateau fractures: Preliminary radiographic and clinical results. Int Orthop 2016;40:1961-1966.

11. Young AA, Neyton L, Molony DC, Boileau P, Walch G. Glenoid tricortical iliac crest structural bone graft enhanced with resorbable cement for the treatment of aseptic glenoid loosening. Tech Shoulder Elb Surg 2011;12:12-17.

12. Charalel RA, McGinty G, Brant-Zawadzki M, Goodwin SC, Khilnani NM, Matsumoto AH, Min RJ, Soares GM, Cook PS. Interventional radiology delivers high-value health care and is an imaging 3.0 vanguard. J Am Coll Radiol 2015;12:501-506.

13. Monsky WL, Khorsand D, Nolan T, Douglas D, Khanna P. Quality of life assessment in interventional radiology. Acad Radiol 2014; 21:407-414.

14. Beall DP, Datir A, D'Souza SL, D'Souza LS, Gunda D, Morelli J, Johnson MB, Nabavizadeh N. Percutaneous treatment of insufficiency fractures. Skeletal Radiol 2010;39:117-130.

15. Hurley MC, Kaakaji R, Dabus G, Shaibani A, Walker MT, Fessler RG, Bendok BR. Percutaneous vertebroplasty. Neurosurg Clin North Am 2009;20:341-359.

16. Marcia S, Boi C, Dragani M, Marini S, Marras M, Piras E, Anselmetti GC, Masala S. Effectiveness of a bone substitute (CERAMENT ${ }^{\mathrm{TM}}$ ) as an alternative to PMMA in percutaneous vertebroplasty: 1-year follow-up on clinical outcome. Eur Spine J 2012; 21:112-118.

17. Masala S, Nano G, Marcia S, Muto M, Fucci FPM, Simonetti G. Osteoporotic vertebral compression fractures augmentation by injectable partly resorbable ceramic bone substitute (Cerament (TM)|SPINE SUPPORT): A prospective nonrandomized study. Neuroradiology 2012;54:589-596.

18. Rauschmann M, Vogl T, Verheyden A, Pflugmacher R, Werba T, Schmidt S, Hierholzer J. Bioceramic vertebral augmentation with a calcium sulphate/hydroxyapatite composite (Cerament (TM) SpineSupport) in vertebral compression fractures due to osteoporosis. Eur Spine J 2010;19:887-892.

19. Siemund R, Nilsson LT, Cronqvist M, Strómqvist B. Initial clinical experience with a new biointegrative cement for vertebroplasty in osteoporotic vertebral fractures. Interv Neuroradiol 2009;15:335340. 
20. Guarnieri G, Vassallo P, Muto M, Muto M. Percutaneous treatment of symptomatic aneurysmal bone cyst of L5 by percutaneous injection of osteoconductive material (Cerament). J Neurointerv Surg 2014;6:e43.

21. Kaczmarczyk J, Sowinski P, Goch M, Katulska K. Complete twelve month bone remodeling with a bi-phasic injectable bone substitute in benign bone tumors: A prospective pilot study. BMC Musculoskelet Disord 2015;16: 369.

22. Despas C, Schnitzler V, Janvier P, Fayon F, Massiot D, Bouler JM, Bujoli B, Walcarius A. High-frequency impedance measurement as a relevant tool for monitoring the apatitic cement setting reaction. Acta Biomater 2014;10:940-950.

23. Thiebaut JM, Roussy G, Chlihi K, Bessiere J. Dielectric study of the activation of blende with cupric ions. J Electroanal Chem 1989;262:131-144.

24. Standard Test Method for Time of Setting of Hydraulic Cement Paste by Gillmore Needles. ASTM C266-89 and ASTM C266-08. Philadelphia: Cement, Lime, Gypsum. American Society for Testing and Materials; 1993.

25. Fung BM, Khitrin AK, Ermolaev K. An improved broadband decoupling sequence for liquid crystals and solids. J Magn Reson 2000;142:97-101.

26. Metz G, Wu XL, Smith SO. Ramped-amplitude cross-polarization in magic-angle-spinning NMR. J Magn Reson Ser A 1994;110:219-127.

27. Massiot D, Fayon F, Capron M, King I, Le Calve S, Alonso B, Durand J-O, Bujoli B, Gan Z, Hoatson G. Modelling one- and twodimensional solid-state NMR spectra. Magn Reson Chem 2002;40: 70-76.

28. Alvarez L, Alcaraz M, Perez-Higueras A, Percutaneous vertebroplasty-Functional improvement in patients with osteoporotic compression fractures. Spine 2006;31:1113-1118.

29. Anselmetti GC, Corrao G, Monica PD, Tartaglia V, Manca A, Eminefendic H, Russo F, Tosetti I, Regge D. Pain relief following percutaneous vertebroplasty: Results of a series of 283 consecu tive patients treated in a single institution. Cardiovasc Interv Radiol 2007;30:441-447.

30. Buchbinder $\mathrm{R}$, Osborne $\mathrm{RH}$, Ebeling PR, Wark JD, Mitchell $P$, Wriedt C, Graves S, Staples MP, Murphy B. A randomized trial of vertebroplasty for painful osteoporotic vertebral fractures. $\mathrm{N}$ Engl J Med 2009;361:557-568.

31. Clark W, Lyon S, Burnes J. Trials of vertebroplasty for vertebral fractures. N Engl J Med 2009;361:2097-2098.

32. Eck JC, Nachtigall D, Humphreys SC, Hodges SD. Comparison of vertebroplasty and balloon kyphoplasty for treatment of vertebral compression fractures: A meta-analysis of the literature. Spine J 2008;8:488-497.

33. Evans AJ, Jensen ME, Kip KE, DeNardo AJ, Lawler GJ, Negin GA Remley KB, Boutin SM, Dunnagan SA. Vertebral compression fractures: Pain reduction and improvement in functional mobility after percutaneous polymethylmethacrylate vertebroplastyretrospective report of 245 cases. Radiology 2003;226:366-372.

34. Hulme PA, Krebs J, Ferguson SJ, Berlemann U. Vertebroplasty and kyphoplasty: A systematic review of 69 clinical studies. Spine 2006;31:1983-2001.

35. Kallmes DF, Comstock BA, Heagerty PJ, Turner JA, Wilson DJ, Diamond TH, Edwards R, Gray LA, Stout L, Owen S, Hollingworth W, Ghdoke B, Annesley-Williams DJ, Ralston SH, Jarvik JG. A randomized trial of vertebroplasty for osteoporotic spinal fractures. N Engl J Med 2009;361:569-579.

36. Klazen $\mathrm{CAH}$, Lohle PNM, de Vries J, Jansen $\mathrm{FH}$, Tielbeek AV, Blonk MC, Venmans A, van Rooij WJJ, Schoemaker MC, Juttmann JR, Lo TH, Verhaar HJJ, van der Graaf $Y$, van Everdingen KJ, Muller AF, Elgersma OEH, Halkema DR, Fransen $H$, Janssens $X$, Buskens $E$, Mali WPThM. Vertebroplasty versus conservative treatment in acute osteoporotic vertebral compression fractures (Vertos II): An open-label randomised trial. Lancet 2010;376:1085-1092.

37. Klazen CAH, Verhaar HJJ, Lampmann LEH, Juttmann JR, Blonk MC, Jansen FH, Tielbeek AV, Schoemaker MC, Buskens E, van der Graaf $Y$, Janssens X, Fransen $H$, van Everdingen KJ, Muller AF, Mali WPThM, Lohle PNM. VERTOS II: Percutaneous vertebroplasty versus conservative therapy in patients with painful osteoporotic vertebral compression fractures; rationale, objectives and design of a multicenter randomized controlled trial. Trials 2007;8: 33.

38. Legroux-Gerot I, Lormeau C, Boutry N, Cotten A, Duquesnoy B, Cortet B. Long-term follow-up of vertebral osteoporotic fractures treated by percutaneous vertebroplasty. Clin Rheumatol 2004;23: 310-317.

39. McGraw JK, Lippert JA, Minkus KD, Rami PM, Davis TM, Budzik RF. Prospective evaluation of pain relief in 100 patients undergoing percutaneous vertebroplasty: Results and follow-up. J Vasc Interv Radiol 2002;13:883-886.

40. Perez-Higueras A, Alvarez L, Rossi RE, Quiñones D, Al-Assir I. Percutaneous vertebroplasty: Long-term clinical and radiological outcome. Neuroradiology 2002;44:950-954.

41. Voormolen MHJ, Lohle PN,Lampmann LE, van den Wildenberg W, Juttmann JR, Diekerhof $\mathrm{CH}$, de Waal Malefijt J. Prospective clinical follow-up after percutaneous vertebroplasty in patients with painful osteoporotic vertebral compression fractures. J Vasc Interv Radiol 2006;17:1313-1320.

42. Zoarski GH, Snow P,Olan WJ, Stallmeyer MJB, Dick BW, Hebel JR, De Deyne M. Percutaneous vertebroplasty for osteoporotic compression fractures: Quantitative prospective evaluation of longterm outcomes. J Vasc Interv Radiol 2002;13:139-148. 